\title{
Características físico-químicas e aceitabilidade de sucos de uva integral de sistemas de produção convencional e orgânico
}

\author{
Mariana Moura Ercolani Novack, Mariane Lobo Ugalde, Gustavo Brunetto, Márcia \\ Arocha Gularte
}

https://doi.org/10.4322/mp.978-65-991393-5-2.c4

\section{Resumo}

Suco de uva integral é o líquido límpido ou turvo extraído da uva por meio de processos tecnológicos adequados, deve apresentar concentração e composição natural, não sendo permitida a adição de açúcar. Objetivou-se com esta pesquisa avaliar a composição físico-química e aceitabilidade do suco de uva integral derivado de sistemas de produção de uva convencional e orgânico. Realizou-se a determinação de umidade, cinzas, proteína bruta, carboidratos totais, $\mathrm{pH}$, sólidos solúveis, acidez total, glicídios redutores em glicose e glicídios não redutores em sacarose, polifenóis totais, análise de cor. Os minerais determinados foram cobre $(\mathrm{Cu})$, zinco $(\mathrm{Zn})$, manganês $(\mathrm{Mn})$, ferro $(\mathrm{Fe})$, cálcio $(\mathrm{Ca})$, magnésio $(\mathrm{Mg})$, fósforo $(\mathrm{P})$ e potássio $(\mathrm{K})$. Realizou-se testes de aceitação sensorial (teste afetivo de aceitação) com julgadores não treinados. Os dados foram submetidos à análise de variância e as médias comparadas pelo teste ' $t$ ' $(p<0,05)$. Através dos resultados pode-se observar que não ocorreu diferença significativa para umidade, cinzas, proteínas, sólidos solúveis totais, acidez total, relação sólidos solúveis/acidez total, Zn e Mn. Observou-se valores superiores $(p<0,05)$ para o suco de uva integral orgânico nas variáveis lipídeos, carboidratos totais, $\mathrm{pH}$, glicídios não redutores em sacarose, polifenóis totais, cobre, cálcio, magnésio, fósforo e potássio. Com esta pesquisa, pode-se concluir que o suco de uva integral orgânico foi aceito entre os julgadores, nos atributos cor, aroma e sabor.

Palavras-chave: análise sensorial, composição bromatológica, legislação, qualidade.

\section{Introdução}

Suco de uva integral é o líquido límpido ou turvo extraído da uva por meio de processos tecnológicos adequados, deve apresentar concentração e composição natural, não sendo permitida a adição de açúcar. É uma bebida não fermentada, de cor, aroma e sabor característicos, submetida a tratamento que assegure sua apresentação e conservação até o momento do consumo (RIZZON, 2007).

Com relação à composição química, o suco de uva possui alto teor de açúcar, glicose e frutose, sendo considerado, um alimento energético. Os ácidos tartárico, málico e cítrico são responsáveis pela acidez do suco, conferindo um pH baixo, e que garante um equilíbrio entre os gostos doce e ácido. Entre os elementos minerais, destacam-se o elevado teor de potássio e o baixo teor de sódio. Encontram-se também no suco de uva o cálcio, magnésio e fósforo em concentrações mais elevadas. O manganês, ferro, 
cobre, zinco, lítio e rubídio estão presentes como microelementos. Encontram-se também compostos fenólicos responsáveis pela cor, adstringência e estrutura, sendo as antocianinas, os taninos e os ácidos fenólicos, os mais importantes. Os compostos voláteis são responsáveis pelo aroma do suco de uva (RIZZON; MIELE, 1995; PINHEIRO et al., 2009).

O sistema convencional é um dos sistemas de produção agrícola no país, cujo processo de produção está baseado no emprego de adubos químicos e agrotóxicos (MEIRELLES; RUPP, 2005). No ponto de vista social, a população tem consumido alimentos com a dosagem de agrotóxicos acima do limite máximo autorizado pela Anvisa (ANVISA, 2014).

Com relação ao sistema orgânico é um método de produção agrícola que dispensa o uso de insumos químicos e se caracteriza por um processo que leva em conta a relação solo/planta/ambiente com o intuito de preservar o meio ambiente, a saúde dos homens e dos animais (MEIRELLES; RUPP, 2005). Sua principal característica é não utilizar agrotóxicos, adubos químicos ou substâncias sintéticas que agridam o meio ambiente (SULZBACH et al., 2013; IFST, 2013). Esse sistema de produção se baseia em normas de produção específicas, cuja finalidade é estabelecer estruturas que sejam sustentáveis, do ponto de vista social, ecológico e econômico (GLIESSMAN, 2009).

A agricultura orgânica vem crescendo rapidamente desde 1990, tanto em área cultivada como em número de produtores e mercado consumidor. O crescimento da agricultura orgânica se deve, principalmente, ao fato da agricultura convencional basear-se na utilização intensiva de produtos químicos e a maior consciência de parcela dos consumidores quanto aos efeitos adversos que os resíduos de produtos químicos podem causar à saúde (SANTOS; MONTEIRO, 2004).

No Brasil a cultura e a comercialização dos produtos orgânicos foram aprovadas pela Lei 10.831, de 23 de dezembro de 2003. No entanto, sua regulamentação, ocorreu apenas em 27 de dezembro de 2007 com a publicação do Decreto n 6.323 (BRASIL, 2014). A produção orgânica, segundo o Ministério da Agricultura, Pecuária e Abastecimento, busca promover a qualidade de vida com proteção ao meio ambiente (SULZBACH et al., 2013; IFST, 2013).

A adoção desse sistema de produção vem crescendo tanto em área cultivada como em número de produtores e mercado consumidor, embora ainda represente uma parcela pequena da agricultura. Os produtos oriundos do sistema de produção orgânico vêm alcançando grande aceitação do público consumidor (MENESES; MESSIAS; BARROS, 2011). Alguns tipos de frutas, por apresentarem alta sensibilidade a pragas e doenças, demanda grande quantidade de agrotóxicos para a produção convencional. Assim, a produção orgânica, além do benefício ao meio ambiente, ao produtor e ao consumidor, permite diferenciar o produto e ampliar 0 mercado e a renda (SULZBACH et al., 2013).

Comparando o sistema convencional com o orgânico, lyama e May (2004) demonstraram que a produtividade média do convencional foi superior ao orgânico. Esse é um dos motivos que faz com que os produtores continuem no sistema convencional. Entretanto, uma avaliação mais ampla aponta para outros horizontes. Analisando os custos fixos totais, por exemplo, percebe-se que o sistema convencional é mais dispendioso. Além disso, os preços pagos ao produtor convencional são menores quando comparados ao orgânico, resultando em receita líquida menor. Em termos de qualidade nutricional e sensorial, os estudos ainda são pouco conclusivos. Pesquisa realizada por Stertz (2004) coletando amostras de frutas 
convencional e orgânico na Região Metropolitana de Curitiba, mostrou que não foram observadas diferenças significativas na acidez, cinzas, vitamina C, apenas nos teores de alguns minerais. Apenas os níveis de açúcares e matéria seca foram maiores no sistema orgânico o que, aparentemente, confere um sabor mais marcante para o consumidor que escolhe um produto orgânico.

É importante ressaltar que existem poucas pesquisas com suco de uva integral orgânico quanto ao aspecto nutricional e sensorial. O estudo objetivou avaliar a composição físico-química e aceitabilidade de sucos de uva integral de sistemas de produção convencional e orgânico.

\section{Materiais e Métodos}

\subsection{Suco de uva}

Dois sucos de uva integrais comerciais, um derivado de uvas de videiras cultivadas em sistema de produção convencional e outro proveniente de uvas de videiras cultivadas em sistema de produção orgânico foram adquiridos. As garrafas com $500 \mathrm{~mL}$ de conteúdo de cada tipo de suco foram obtidas em triplicata, em uma vinícola localizada em Bento Gonçalves, Rio Grande do Sul, região Sul do Brasil, ambas da safra 2015. No rótulo dos produtos não constava as cultivares das uvas utilizadas para elaboração dos sucos.

\subsection{Preparo das amostras e análises físico-químicas}

A determinação de umidade (U), cinzas (CZ), lipídeos (LIP), proteína bruta (PB) e carboidratos totais (CT) foram realizadas de acordo com a metodologia descrita pela AOAC (1995). Assim, as cinzas foram obtidas por meio da incineração da amostra em cadinhos de porcelana na mufla a $550{ }^{\circ} \mathrm{C}$ por 5 horas. O teor de proteína bruta foi determinado pelo método de Kjedahl. Os lipídeos foram determinados pelo método de Bligh e Dyer (1959). A fração de carboidrato total foi estimada pela equação 1:

$$
\text { CT }(\%)=100-(\% U+\% C Z+\% \text { LIP }+\% P B)
$$

A determinação do $\mathrm{pH}$ foi realizada em medição com potenciômetro automático (Digimed, modelo DM-22), após calibração do aparelho com tampões de pH 4,00 e 7,00, diretamente no líquido (INSTITUTO ADOLFO LUTZ, 2008). Os sólidos solúveis totais foram determinados através da leitura em refratômetro portátil (Instrutherm) com correção automática de temperatura, os valores foram expressos em ${ }^{\circ}$ Brix (INSTITUTO ADOLFO LUTZ, 2008).

A determinação da acidez total foi realizada por titulação com solução de $\mathrm{NaOH}$ 0,1 mol. $\mathrm{L}^{-1}$, tendo como indicador fenolftaleína, e os resultados expressos em $\mathrm{g}$ de ácido tartárico.100 $\mathrm{mL}^{-1}$ de suco (INSTITUTO ADOLFO LUTZ, 2008).

Os glicídios redutores em glicose e glicídios não redutores em sacarose foram determinados conforme metodologia proposta por Instituto Adolfo Lutz (2008).

A concentração de polifenóis totais foi determinada por meio da reação do suco de uva com reagente de Folin Ciocalteau, a leitura da absorbância em comprimento de onda de $765 \mathrm{~nm}$ (SINGLETON; ROSSI, 1965). Os resultados foram expressos em equivalentes de ácido gálico (mg. $\left.\mathrm{L}^{-1} \mathrm{EAG}\right)$. 
A cor foi analisada em colorímetro (Konica Minolta CR-200), o qual foi calibrado com placa de porcelana branca. Três parâmetros de cor foram analisados: $L^{*}, a^{*}$ e $b^{*}$. $O$ valor $L$ fornece a luminosidade, variando do branco $(L=100)$ ao preto $(L=0)$. O valor de $a^{*}$ caracteriza coloração na região do vermelho $\left(+a^{*}\right)$ ao verde $\left(-a^{*}\right)$, o valor $b^{\star}$ indica coloração no intervalo do amarelo $\left(+b^{\star}\right)$ ao azul $\left(-b^{\star}\right)$.

Os minerais determinados foram cobre $(\mathrm{Cu})$, zinco $(\mathrm{Zn})$, manganês $(\mathrm{Mn})$, ferro $(\mathrm{Fe})$, cálcio $(\mathrm{Ca})$, magnésio $(\mathrm{Mg})$, fósforo $(\mathrm{P})$ e potássio $(\mathrm{K})$, utilizando espectrometria de emissão óptica em plasma indutivamente acoplado (ICPOES) (MORGANO; QUEIROZ; FERREIRA, 1999).

Amostras dos sucos foram submetidas à digestão nitro-perclórica para a determinação dos teores totais de cálcio $(\mathrm{Ca})$, magnésio $(\mathrm{Mg})$, fósforo $(\mathrm{P})$, potássio $(\mathrm{K})$, cobre $(\mathrm{Cu})$, zinco $(\mathrm{Zn})$, manganês $(\mathrm{Mn})$ e ferro $(\mathrm{Fe})$, conforme metodologia proposta por (EMBRAPA, 1999). As leituras das concentrações totais de $\mathrm{Cu}, \mathrm{Zn}, \mathrm{Fe}, \mathrm{Mn}, \mathrm{Ca}$ e $\mathrm{Mg}$ foram realizadas em espectrofotômetro de absorção atômica (EAA; Varian SpectrAA600 , Austrália). A concentração de $K$ foi determinada em fotômetro de chama (B262 Micronal). A concentração de P foi determinada conforme Murphy e Riley (1962), no comprimento de onda de $880 \mathrm{~nm}$, em espectrofotômetro UV-visível (1105, Bel Photonics).

\subsection{Análise sensorial}

Para a avaliação sensorial dos sucos foram realizados testes de aceitação sensorial (teste afetivo de aceitação), utilizando uma equipe composta por 70 julgadores não treinados, com idade entre 18 a 55 anos de ambos os gêneros, pertencentes ao Instituto Federal Farroupilha Campus Júlio de Castilhos. Aos consumidores foi requisitado avaliar os atributos: cor, aroma e sabor, por meio de escala hedônica de 9 pontos, sendo os extremos 1 desgostei muitíssimo e 9 gostei muitíssimo.

O índice de aceitabilidade (IA) foi determinado em relação aos atributos cor, aroma e sabor, sendo calculado pela equação 2 .

$\mathrm{IA}(\%)=\mathrm{A} \times 100 / \mathrm{B}$

(Equação 2)

Em que: $\mathrm{A}=$ valor da média obtida para o produto, $\mathrm{B}=$ ponto máximo da escala.

O IA com potencial mercadológico tem sido considerado $\geq 70$ \% (BISPO et al., 2004).

\subsection{Análise estatística}

Os dados foram submetidos à análise de frequência e variância (ANOVA) e as médias quando significativas foram comparadas pelo teste ' $t$ ' $(p<0,05)$, utilizando-se 0 "software" ASSISTAT versão 7.7 beta.

\section{Resultados e Discussão}

A análise estatística dos dados para a composição físico-química do suco de uva integral convencional e orgânico está apresentada na Tabela 1.

Com relação à umidade dos sucos pode-se observar que não ocorreu diferença significativa para os sucos integrais orgânicos e convencionais, contendo acima de $87 \%$ de umidade. 
Tabela 1. Composição físico-química de suco de uva integral convencional e orgânico.

\begin{tabular}{|c|c|c|}
\hline \multirow[b]{2}{*}{ Variável } & \multicolumn{2}{|c|}{ Suco integral } \\
\hline & Convencional & Orqânico \\
\hline Umidade (\%) & $87,77 \pm 0,34^{\mathrm{ns}}$ & $87,04 \pm 0,41$ \\
\hline Cinzas (\%) & $1.58 \pm 0.20^{\mathrm{ns}}$ & $1,30 \pm 0.21$ \\
\hline Proteínas (\%) & $0,21 \pm 0,09^{\text {ns }}$ & $0,18 \pm 0,01$ \\
\hline Lipídeos (\%) & $0,10 \pm 0,00^{b}$ & $0,15 \pm 0,03^{\mathrm{a}}$ \\
\hline Carboidratos totais (\%) & $10,35 \pm 0,41^{b}$ & $11,33 \pm 0,18^{a}$ \\
\hline $\mathrm{pH}$ & $3,32 \pm 0,09^{b}$ & $3,55 \pm 0,13^{\mathrm{a}}$ \\
\hline Sólidos solúveis totais ( $\left.{ }^{\circ} \mathrm{Brix}\right)$ & $17,00 \pm 0,00^{\text {ns }}$ & $18,00 \pm 0,00$ \\
\hline Acidez total (g.100mL ${ }^{-1}$ de ácido tartárico) & $0,73 \pm 0,03^{\text {ns }}$ & $0,85 \pm 0,08$ \\
\hline Relação sólidos solúveis/acidez total & $23,46 \pm 0,03^{\text {ns }}$ & $21,21 \pm 0,08$ \\
\hline Glicídios redutores em glicose g (\%) & $13,67 \pm 0,12^{a}$ & $12,75 \pm 0,13^{b}$ \\
\hline Glicídios não redutores em sacarose g (\%) & $0,26 \pm 0,08^{b}$ & $0,54 \pm 0,03^{\mathrm{a}}$ \\
\hline Polifenóis totais (mg. $\mathrm{L}^{-1} \mathrm{EAG}$ ) & $474,58 \pm 11,59^{b}$ & $596,08 \pm 1,44^{\mathrm{a}}$ \\
\hline$L^{*}$ & $24,56 \pm 4,12^{\mathrm{a}}$ & $13,27 \pm 0,78^{b}$ \\
\hline$a^{*}$ & $58,01 \pm 2,49^{a}$ & $48,97 \pm 1,37^{b}$ \\
\hline$b^{*}$ & $26,98 \pm 1,50^{a}$ & $12,67 \pm 1,25^{\mathrm{b}}$ \\
\hline $\mathrm{Cu}\left(\mathrm{mg} \cdot \mathrm{L}^{-1}\right)$ & $3,56 \pm 0,03^{b}$ & $5,38 \pm 0,05^{\mathrm{a}}$ \\
\hline $\mathrm{Zn}\left(\mathrm{mg} \cdot \mathrm{L}^{-1}\right)$ & $1,42 \pm 0,29$ & $2,12 \pm 0,33$ \\
\hline $\mathrm{Mn}\left(\mathrm{mg} \cdot \mathrm{L}^{-1}\right)$ & $2,26 \pm 0,06$ & $2,39 \pm 0,02^{\text {ns }}$ \\
\hline $\mathrm{Fe}\left(\mathrm{mg} \cdot \mathrm{L}^{-1}\right)$ & $3,38 \pm 0,57^{\mathrm{a}}$ & $1,51 \pm 0,77^{\mathrm{b}}$ \\
\hline $\mathrm{Ca}\left(\mathrm{mg} \cdot \mathrm{L}^{-1}\right)$ & $170,56 \pm 6,74^{b}$ & $208,04 \pm 9,97^{\mathrm{a}}$ \\
\hline $\mathrm{Mg}\left(\mathrm{mg} \cdot \mathrm{L}^{-1}\right)$ & $210,21 \pm 7,73^{\mathrm{b}}$ & $242,49 \pm 7,49^{a}$ \\
\hline$P\left(m g \cdot L^{-1}\right)$ & $139,91 \pm 3,06^{\mathrm{b}}$ & $242,99 \pm 12,13^{a}$ \\
\hline $\mathrm{K}\left(\mathrm{mg} \cdot \mathrm{L}^{-1}\right)$ & $1338,70 \pm 19,05^{b}$ & $1767,70 \pm 83,05^{a}$ \\
\hline
\end{tabular}

Médias seguidas de letras diferentes na linha, diferem entre si ao nível de $5 \%$, segundo o teste de ' $\mathrm{t}$ '.

ns: não significativo.

Não houve diferença $(p<0,05)$ quanto ao teor de cinzas. A concentração proteica média das amostras de suco de uva integral orgânico foi de $0,18 \%$ e no suco de uva integral convencional foi de 0,21\%. Como esperado, detectou-se pequenas concentrações de cinzas e proteínas. Aparentemente, a razão principal do consumo de produtos orgânicos é a percepção que apresentam maior valor nutricional em relação aos cultivados de forma convencional, embora poucas evidências possam ser identificadas, a não ser a possibilidade de não conter resíduos químicos (BORDELEAU et al., 2002).

O suco de uva integral orgânico apresentou o maior teor de lipídeos (0,15\%), estatisticamente diferente do suco de uva integral convencional $(0,10 \%)$. Ao analisar os resultados da comparação de médias para carboidratos totais nos diferentes sucos, foram verificadas diferenças $(p<0,05)$ nos valores de $11,33 \%$ para suco de uva integral orgânico e 10,35\% para suco de uva integral convencional. Os sucos são constituídos principalmente por açúcares como glicose e frutose.

Segundo Rizzon et al. (1998) os valores de referência para o pH do suco de uva são de no mínimo de 2,80 e máximo de 3,43 . No presente estudo os resultados evidenciaram diferença significativa para o $\mathrm{pH}$, sendo de 3,55 no suco de uva integral orgânico e 3,32 no suco de uva integral convencional. Presume-se que o valor de pH mais elevado no suco orgânico seja em função dos menores teores de ácidos orgânicos presente na uva utilizada para elaboração desse suco. Ferreira et al. (2010) constataram que as amostras cultivadas no sistema orgânico apresentaram valores 
mais elevados do $\mathrm{pH}$, quando comparados ao sistema convencional, levando a crer que as amostras cultivadas nesse sistema apresentam menor acidez, característica importante para a aceitação do produto.

Os sólidos solúveis totais dos sucos apresentaram resultados entre 17,00 e 18,00 'Brix, não diferindo $(p<0,05)$ entre orgânico e convencional. A legislação brasileira prevê o mínimo de $14^{\circ}$ Brix para sólidos solúveis totais para sucos, no qual a uva deve atingir um grau de maturação adequado para sua elaboração (BRASIL, 2004). Dessa forma os sucos analisados no presente estudo estão de acordo com o valor de referência previsto na legislação. Observaram-se resultados semelhantes para a acidez total entre os sucos de uva integral orgânico e convencional, com valores respectivos de 0,85 e $0,73 \mathrm{~g} .100 \mathrm{~mL}^{-1}$ de ácido tartárico. Os resultados apresentam-se dentro do limite máximo que é $0,9 \%$ de acidez total em gramas de ácido tartárico, determinado pela legislação brasileira para sucos (BRASIL, 2004). A maturação faz com que a acidez diminua devido à queda na concentração de ácidos málico e tartárico (LEITE, 2013).

Quando avaliada a relação entre sólidos solúveis e acidez total observaram-se valores de 21,21 para suco de uva integral orgânico e 23,46 para suco de uva integral convencional. Portanto, valores mais elevados representam sucos de uva menos ácidos. Conforme Pezzi e Fenocchio (1976) a relação ${ }^{\circ}$ Brix/acidez total representa o equilíbrio entre o gosto doce e ácido do suco de uva, dessa forma, um indicativo de qualidade de suco de uva. Essa relação propicia uma boa avaliação do sabor, a qual é mais importante do que realizar de forma isolada a medição de açúcares e acidez (HENRIQUE, 2015). No Brasil a legislação estabelece limites entre 15 e 45 (BRASIL, 1974), sendo que valores mais próximos do mínimo demonstram que o suco apresenta acidez considerável, enquanto que valores mais elevados representam sucos menos ácidos.

Os valores médios de glicídios redutores em glicose variaram significativamente entre os dois produtos analisados. O suco de uva convencional apresentou o maior valor de glicídios redutores em glicose (13,67\%). Estudo realizado por Pinheiro (2008) com suco de uva os valores de glicídios redutores variaram entre 7,9 a 10,5\%, enquanto Freitas et al. (2006), obteve valores semelhantes ao do presente estudo de $13,3 \%$. Os monossacarídeos podem ser oxidados por agentes oxidantes, tais como íons férricos (Fe) e cúprico (Cu). O carbono do grupo carbonila é oxidado a ácido carboxílico, formando os ácidos aldônicos, geralmente em meio alcalino. As extremidades alcoólicas dos carboidratos podem ser oxidadas por enzimas específicas formando os ácidos aldurônicos, que são importantes constituintes de polissacarídeos. A glicose e outros açúcares que possuem carbonila livre ou potencialmente livre são capazes de reduzir os íons férricos ou cúprico, e dessa forma são chamados de açúcares redutores (BOBBIO; BOBBIO, 2003).

Quanto ao teor de glicídios não redutores em sacarose observou-se que ocorreu diferença significativa entre as amostras avaliadas. O suco de uva orgânico apresentou o maior valor 0,54\%. Dessa forma, percebe-se que o fabricante dos sucos não faz a adição de açúcar (sacarose) na constituição desses sucos; visto que, em uvas normalmente o valor de glicídios não redutores é muito baixo ou zero (SANTANA et al., 2008).

Os dados apresentaram maior média de polifenóis, no suco de uva integral orgânico $\left(596,08 \mathrm{mg} \cdot \mathrm{L}^{-1} \mathrm{EAG}\right)$, sendo esta diferente $(p<0,05)$ do suco de uva integral convencional (474,58 mg. $\mathrm{L}^{-1}$ EAG). Conforme Malacrida e Motta (2005) essa variação de polifenóis pode ser em função da variedade de uva utilizada no processamento do suco, maturidade, regiões e práticas de cultivo das mesmas. Segundo pesquisa, 
sugere-se que os dois tipos de suco uva (convencional e orgânico) apresentam intensa propriedade antioxidante com forte correlação positiva com a concentração de polifenóis, podendo assumir que o suco de uva possui atividade hepatoprotetora (DANI et al., 2008).

O suco de uva convencional com coloração mais clara, obteve um índice de luminosidade significativamente maior $(24,56)$ quando comparado com o suco orgânico $(13,27)$. Com relação aos valores obtidos para $a^{\star}$, componente de cor que varia de verde (-) a vermelho (+), em ambos os sucos houve a tendência para a intensidade vermelha, sendo que no convencional o valor foi superior $(p<0,05)$ ao orgânico. O valor de $b^{*}$ indica uma coloração do orgânico $(12,67)$ mais próxima do azul, quando comparado com o convencional $(26,98)$. Conforme Chitarra e Alves (2001) a cor é o atributo de qualidade mais atrativo para o consumidor, sendo que os produtos com coloração forte e brilhante são os preferidos, entretanto, na maioria dos casos, a cor não está correlacionada com o valor nutricional e a qualidade do produto. Em relação a composição de minerais do suco de uva integral, considerando o efeito do cultivo convencional e orgânico, verificou-se diferença significativa para os elementos: $\mathrm{Cu}, \mathrm{Fe}, \mathrm{Ca}, \mathrm{Mg}, \mathrm{P}$ e K (Tabela 1).

Ao analisar os resultados da comparação das médias de $\mathrm{Cu}$, observou-se que no suco orgânico o valor foi significativamente superior $\left(5,38 \mathrm{mg}^{-\mathrm{L}^{-1}}\right)$. Rizzon e Link (2006) relatam que o teor de $\mathrm{Cu}$ pode sofrer influência em função da maior proporção de película da casca, devido ao menor tamanho da baga.

Entre os sucos analisados, o convencional apresentou o maior teor de ferro, atingindo valores médios de $3,38 \mathrm{mg} \cdot \mathrm{L}^{-1}$ quando comparado com o orgânico que obteve 1,51 $\mathrm{mg} \cdot \mathrm{L}^{-1}$. Já a concentração de Ca foi superior no suco orgânico $\left(208,04 \mathrm{mg} \cdot \mathrm{L}^{-1}\right)$ em comparação ao convencional $\left(170,56 \mathrm{mg}^{-1} \mathrm{~L}^{-1}\right.$. Quanto ao teor de $\mathrm{Mg}$, os valores médios mostraram diferença $(p<0,05)$ entre os sucos analisados, no qual o suco de uva orgânico apresentou valor de $242,49 \mathrm{mg} \cdot \mathrm{L}^{-1}$ e o convencional $210,21 \mathrm{mg} \cdot \mathrm{L}^{-1}$. Na análise de fósforo o maior valor foi detectado para o suco de uva orgânico $(242,99$ mg. $\left.\mathrm{L}^{-1}\right)$ diferindo do convencional $\left(139,91 \mathrm{mg} \cdot \mathrm{L}^{-1}\right)$. Os resultados médios de $\mathrm{K}$ evidenciam diferença significativa entre o suco convencional e orgânicos, com valores de 1338,70 e $1767,70 \mathrm{mg} \cdot \mathrm{L}^{-1}$, respectivamente.

Conforme estudo de Berri e Pelisser (2016) no qual realizou um comparativo entre alimentos orgânicos e convencionais com base em artigos científicos, verificou que existe pouca influência dos valores físico-químicos em relação ao tipo de cultivo (convencional e orgânico).

Com relação a análise sensorial dos 70 julgadores que participaram da avaliação, 51\% eram do sexo feminino e $49 \%$, masculino. Na tabela 2 estão apresentados os valores hedônicos médios para os atributos cor, aroma e sabor. Observou-se que houve diferença significativa nos atributos cor, aroma e sabor, com maior preferência do suco orgânico em todos os atributos quando comparado ao suco de uva convencional. A cor é de fundamental importância, pois está ligada à atratividade para o consumidor (MATSUURA; CARDOSO; RIBEIRO, 2002). Conforme Martins (2010) a preferência pelos orgânicos com relação ao sabor pode ser em função que estes mantêm os ácidos orgânicos, substâncias determinantes do sabor, cuja síntese é reduzida sob altas concentrações de fertilizantes nitrogenados prontamente solúveis, utilizados no sistema convencional. Vários fatores podem influenciar no sabor e aroma de um produto agrícola: a variedade utilizada, tipo de solo, clima e o modo de produção (convencional ou orgânico) (DAROLT, 2002). 
Tabela 2. Valores hedônicos médios para os atributos de cor, aroma e sabor de suco de uva integral convencional e orgânico.

\begin{tabular}{lcc}
\hline & \multicolumn{2}{c}{ Suco integral } \\
\cline { 2 - 3 } Atributos & Convencional & Orgânico \\
\hline Cor & $6,79 \pm 1,40^{\mathrm{b}}$ & $8,07 \pm 1,51^{\mathrm{a}}$ \\
Aroma & $6,79 \pm 1,61^{\mathrm{b}}$ & $7,79 \pm 1,68^{\mathrm{a}}$ \\
Sabor & $6,78 \pm 1,47^{\mathrm{b}}$ & $7,84 \pm 1,69^{\mathrm{a}}$ \\
\hline
\end{tabular}

Médias seguidas de letras diferentes na linha diferem entre si ao nível de $5 \%$, segundo o teste de ' $\mathrm{t}$ '.

Os resultados da avaliação sensorial por escala hedônica apresentaram, que os sucos de uva orgânico foram caracterizados entre as descrições 'gostei muito a gostei extremamente'.

Pesquisa realizada por Meneses, Messias e Barros (2011) com suco de uva orgânico apontaram o valor médio na preferência do julgador de 5,79. Destacou-se que 35,7\% dos julgadores citaram, que o sabor característico do mesmo foi o atributo que mais agradou, enquanto que $11,9 \%$ citaram que o sabor amargo foi o atributo que menos agradou para os dois sucos.

Os índices de aceitabilidade verificados para os sucos de uva convencional e orgânicos estão apresentados na Tabela 3.

Tabela 3. Índice de aceitabilidade (\%) dos sucos de uva integral e orgânico segundo cada atributo.

\begin{tabular}{lcc}
\hline Atributos & \multicolumn{2}{c}{ Suco integral } \\
\cline { 2 - 3 } & Convencional & Orgânico \\
\hline Cor & 75,44 & 89,66 \\
Aroma & 75,44 & 86,56 \\
Sabor & 75,33 & 87,11 \\
\hline
\end{tabular}

Os resultados para o índice de aceitabilidade do suco de uva convencional variaram de 75,33 a $75,44 \%$ entre os atributos avaliados. Já no suco de uva orgânico ele variou de 86,56 a 89,66\% entre os atributos cor, aroma e sabor. Segundo Bispo et al. (2004) os sucos de uva convencional e orgânicos demonstraram uma repercussão favorável ao consumo, pois obtiveram valores superiores a 70\%. O suco de uva orgânico se destacou em todos os atributos sensoriais de aceitação avaliado, pois obteve notas mais altas em cor, aroma e sabor.

\section{Conclusão}

O suco de uva integral derivado de sistema de produção orgânico mostrou valores superiores para as variáveis lipídeos, carboidratos totais, $\mathrm{pH}$, glicídios não redutores em sacarose, polifenóis totais, cobre, cálcio, magnésio, fósforo e potássio.

O suco de uva integral orgânico apresentou uma melhor aceitação entre os julgadores, nos atributos cor, aroma e sabor. 
Os sucos de uva integral produzidos pelo sistema convencional e orgânico apresentam os padrões de qualidade previstos na legislação brasileira vigente. Os parâmetros de qualidade nutricional e sensorial são multifatoriais, pois condições de solo, clima e variedade, podem apresentar diferenças significativas entre o modo de produção convencional e o orgânico. Sugerem-se novas pesquisas envolvendo sucos de uva integral convencional e orgânico, aumentando assim, o conhecimento da composição nutricional desses produtos.

\section{Referências}

ANVISA. Programa de análise de resíduos de agrotóxicos em alimentos. Disponível em:<http://portal.anvisa.gov.br/wps/wcm/connect/d480f50041ebb7a09db8bd3e2b7e7e 4d/Relatório\%2BPARA\%2B2011-12\%2B-\%2B30_10_13_1.pdf?MOD=AJPERES>. Acesso 28 dez. 2021.

ASSOCIATION OF OFFICIAL ANALYTICAL CHEMISTS - AOAC. Official methods of analysis. 16 th ed. Virgínia: AOAC Internacional, 1995. V. 1.

BERRI, A.S.; PELISSER, M.R. Diferenças bromatológicas nos sistemas de produção de alimentos orgânicos e convencionais: uma revisão sistemática. Revista Maiêutica, v. 4, n. 1, p. 89-114, 2016.

BISPO, E. S. et al. Processamento, estabilidade e eceitabilidade de marinado de vongole. Revista Ciência e Tecnologia de Alimentos. v. 24, n. 3, p. 353-356, 2004. https://doi.org/10.1590/S0101-20612004000300008.

BLIGH, E. G.; DYER, W. J. A rapid method of total lipid extration and purification. Canadian Journal of Physiology and Pharmacology, v. 37, p. 911-917, 1959. https://doi.org/10.1139/y59-099.

BOBBIO, F.O.; BOBBIO, P.A. Introdução a química de alimentos. 3. ed. São Paulo: Varela, 2003.

BORDELEAU, G., et al. Food quality: a comparison of organic and conventional fruits and vegetables. Ecol Agric - Den Kongelige Veterinoer -og Landbohojskole. 2002. p.1-82.

BRASIL. Ministério da Agricultura e do Abastecimento. Portaria $\mathrm{n}^{\circ} 55$, de 27 de julho de 2004. Normas referentes à complementação dos padrões de identidade e qualidade do vinho e dos derivados da uva e do vinho. Diário Oficial [da] República Federativa do Brasil. Brasília, 27 de julho de 2004.

BRASIL. Ministério da Agricultura. Secretaria Nacional de Defesa Agropecuária. Secretaria de Inspeção de Produtos Vegetal. Complementação de padrões de identidade e qualidade para suco, refresco e refrigerante de uva. Brasília, 1974. 29p.

CHITARRA, A.B.; ALVES, R.E. Tecnologia de pós-colheita para frutas tropicais. Fortaleza: FRUTAL - SINDIFRUTA, 2001.

DANI, C. et al. Intake of purple grape juice as a hepatoprotective agent in Wistar rats. Journal Medicinal Food, v. 11, n. 1, p. 127-132, 2008. https://doi.org/10.1089/jmf.2007.558. 
DAROLT, M.R. Comparação entre a qualidade de alimentos orgânicos e convencionais. $2002 . \quad$ Disponível em: $<\mathrm{ftp}$ ://ftp.cidasc.sc.gov.br/agroecologia/Moacir\%20Darolt\%20Cap\%20 Qualidade\%202009.pdf>. Acesso em: 23 abr. 2017.

FERREIRA, R.M.S. et al. Qualidade do tomate de mesa cultivado no sistema convencional e orgânico. Revista Ciência e Tecnologia de Alimentos, v. 30, n.1, p. 224-230, 2010. Disponível em: <https://core.ac.uk/download/pdf/208598151.pdf>. Acesso em: 23 abr. 2017.

FREITAS, C.A.S. et al. Estabilidade do suco tropical de acerola (Malpighia emarginata D.C.) adoçado envasado pelos processos hot-fill e asséptico. Revista Ciência e Tecnologia de Alimentos, v. 26, n. 3, p. 544-549, 2006. Disponível em: <https://www.redalyc.org/articulo.oa?id=395940079010>. Acesso em: 23 abr. 2017.

GLIESSMAN, S. R. Agroecologia: processos ecológicos em agricultura sustentável. 4. ed. Porto Alegre: UFRGS, 2009.

HENRIQUE, P.C. Radiação ultravioleta (UV-C) em sucos de uva integral. 2015. 93f. Tese (Doutorado em Ciência e Tecnologia dos Alimentos) - Universidade Federal de Lavras, Lavras, 2015.

IFST - Institute of Food Science and Technology (2013). Organic food. Disponível em www.ifst.org/document.aspx?id=386. Acesso em: 21 de abril de 2016.

INSTITUTO ADOLFO LUTZ. Métodos físico-químicos para análise de alimentos. São Paulo: Instituto Adolfo Lutz, 2008.

IYAMA, J.T.; MAY, P.H. Valoração econômica do meio ambiente: Comparação da Agricultura Química Versus Agricultura Natural. In: Congresso Acadêmico de Meio Ambiente e Desenvolvimento do Rio de Janeiro. Anais... Congresso Acadêmico de Meio Ambiente e Desenvolvimento do Rio de Janeiro, Rio de Janeiro, 1. 2004.

LEITE, B.F. Suco de uva: propriedades organolépticas, produção e legislação. 2013. 27 f. Monografia (Graduação) - Escola de Engenharia de Lorena da Universidade de São Paulo, São Paulo, 2013.

MALACRIDA, C.R.; MOTTA, S. Compostos fenólicos totais e antocianinas em suco de uva. Revista Ciência e Tecnologia de Alimentos, v. 25, n.4, pp.659-664, 2005. https://doi.org/10.1590/S0101-20612005000400006.

MARTINS, C.R. et al. Qualidade sensorial de maças produzidas em diferentes sistemas de produção. Revista Scientia Agraria, v.11, n.2, p.091-099, 2010. Disponível em: <https://revistas.ufpr.br/agraria/article/view/16526/11447>. Acesso em: 23 abr. 2017.

MATSUURA, F.C.A.U.; CARDOSO, R.L.; RIBEIRO, D.E. Qualidade sensorial de frutos de híbridos de bananeira cultivar Pacovan. Revista Brasileira de Fruticultura, Jaboticabal, v. 24, n. 1, p. 263-266, 2002. http://dx.doi.org/10.1590/S010029452002000100058.

MENESES, F.; MESSIAS, G.M.; BARROS, N.E. Análise sensorial de suco de uva orgânico: teste de aceitação. Revista Eletrônica Novo Enfoque, v. 12, n. 12, p. 0105, 2011. 
MEIRELLES, L.R.; RUPP, L.C.D. Agricultura ecológica: princípios básicos. Cartilha do Centro Ecológico de Ipê, 2005. 76p. Disponível em http://www.permaculturaahia.org.br/artigos/Cartilha_Agricultura_Ecologica.pdf.

MORGANO, M.A.; QUEIROZ, S.C.N.; FERREIRA, M.M.C. Determinação dos teores de minerais em sucos de frutas por espectrometria de emissão óptica em plasma indutivamente acoplado (ICP-OES). Revista Ciência e Tecnologia de Alimentos, v.19, n.3, p.344-348, 1999. http://dx.doi.org/10.1590/S0101-20611999000300009.

MURPHY, J.; RILEY, J. P. A Modified single solution method for determination of phosphate in natural waters. Analytica Chemical Acta, n. 27, p. 31-36, 1962. https://doi.org/10.1016/S0003-2670(00)88444-5.

PEZZI, G.M.; FENOCCHIO, P. Estudo analítico dos sucos de uva comerciais. Pesquisa Agropecuária Brasileira, v. 11, p.11-13, 1976. Disponível em: $<$ https://seer.sct.embrapa.br/index.php/pab/article/view/16911>. Acesso em: 28 dez. 2020.

PINHEIRO, E.S. Avaliação dos aspectos sensoriais, físico-químicos e minerais do suco de uva da variedade benitaka (Vitis vinífera L.). 2008. 106 f. Dissertação (Mestrado em Tecnologia de Alimentos) - Universidade Federal do Ceará, Fortaleza, 2008.

PINHEIRO, E.S. et al. Estabilidade físico-química e mineral do suco de uva obtido por extração a vapor. Revista Ciência Agronômica, v. 40, n. 3, p. 373-380, 2009. Disponível em: <http://ccarevista.ufc.br/seer/index.php/ccarevista/article/view/756>. Acesso em: 28 dez. 2020.

RIZZON, L.A. et al. Elaboração de suco de uva na propriedade vitícola. Bento Gonçalves: Embrapa Uva e Vinho, 1998. 24p.

RIZZON, L.A. Suco de uva. Brasília, DF: Embrapa Informação Tecnológica, 2007. 45 $\mathrm{p}$

RIZZON, L.A.; LINK, M. Composição do suco de uva caseiro de diferentes cultivares. Revista Ciência Rural, v. 36, p. 689-692, 2006. https://doi.org/10.1590/S010384782006000200055 .

RIZZON, L.A.; MIELE, A. Características analíticas de sucos de uva elaborados no Rio Grande do Sul. Boletim Sociedade Brasileira de Ciência e Tecnologia de Alimentos, v.29, n.2, p.129-133, 1995.

SANTANA, M.T.A. et al. Caracterização de diferentes marcas de sucos de uva comercializados em duas regiões do Brasil. Revista Ciência e Agrotecnologia, v. 32, p. 882-886, 2008. http://dx.doi.org/10.1590/S1413-70542008000300027.

SANTOS, G. C.; MONTEIRO, M. Sistema orgânico de produção de alimentos. Revista Alimentos e Nutrição, v.15, n.1, p.73-86, 2004. Disponível em: <http://servbib.fcfar.unesp.br/seer/index.php/alimentos/article/viewArticle/59>. Acesso em: $28 \mathrm{dez}$. 2020.

SULZBACH, A. et al. Ação educativa do projeto Embrapa 40+20: morangos orgânicos. Brasília: Embrapa Uva e Vinho, 2013. 12p.

SINGLETON, V.L.; ROSSI, J.A. Colorimetry of total phenolics with phosphomolybdic- 
phosphotungstic acid reagents. American Journal of Enology and Viticulture, v. 16, n. 3, p. 144-158, 1965. Disponível em: <https://www.ajevonline.org/content/16/3/144>. Acesso em: 28 dez. 2020.

STERTZ, S. C. Qualidade de hortícolas convencionais, orgânicas e hidropônicas na Região Metropolitana de Curitiba - Paraná. 2004. 260 f. Tese (Doutorado) Universidade Federal do Paraná, Setor de Tecnologia, Curitiba, 2004.

\section{Agradecimentos}

As instituições de ensino, Instituto Federal Farroupilha Campus Júlio de Castilhos, Universidade Federal de Pelotas e Universidade Federal de Santa Maria, pelo empréstimo de equipamentos e fornecimento de materiais que foram fundamentais para o desenvolvimento da pesquisa que possibilitou a realização deste trabalho.

\section{Autores}

Mariana Moura Ercolani Novack ${ }^{1, *}$, Mariane Lobo Ugalde ${ }^{2}$, Gustavo Brunetto ${ }^{3}$, Márcia Arocha Gularte $^{4}$

1. Curso de Pós-graduação Lato Sensu em Ciência dos Alimentos, Centro de Ciências Químicas, Farmacêuticas e de Alimentos, Universidade Federal de Pelotas, Campus Universitário, Caixa Postal, 354, 96010-900, Pelotas, RS, Brasil.

2. Eixo Produção Alimentícia, Instituto Federal Farroupilha Campus Júlio de Castilhos, RS-527, s/n, Distrito de São João do Barro Preto, 98130-000, Júlio de Castilhos, Brasil

3. Departamento de Solos, Universidade Federal de Santa Maria, Av. Roraima $n^{0} 1000$, Cidade Universitária, Camobi, 97105-900, Santa Maria, Brasil

4. Centro de Ciências Químicas, Farmacêuticas e de Alimentos, Universidade Federal de Pelotas, Campus Universitário, Caixa Postal, 354, 96010-900, Pelotas, RS, Brasil

* Autor para correspondência: mariananovack@gmail.com 